\title{
Multiple Dural Arteriovenous Fistulas Manifesting as Progressive Otalgia and Tinnitus and Treated Using a Single Session of Endovascular Embolization
}

This article was published in the following Dove Press journal:

Clinical Interventions in Aging

\begin{abstract}
Abdulrahman Hamad AlAbdulwahhab (1) ${ }^{1,2}$

Sari Al-Suhibani (iD)

Abdulaziz Mohammad AlSharydah (D) '

Saeed Ahmad Al-Jubran'

Moath Abdullah Al-

Thuneyyan'

'Department of Diagnostic and Interventional Radiology, King Fahd Hospital of the University, Imam Abdulrahman Bin Faisal University, Khobar City, Eastern Province, Saudi Arabia; ${ }^{2}$ Department of Radiology, Research Institute of Radiology, Asan Medical Center, University of Ulsan College of Medicine, Seoul, Korea
\end{abstract}

Background: Multiple cranial dural arteriovenous fistulas (dAVFs) are considered to be an uncommon vascular condition. dAVFs usually manifest with vague symptoms, which are related to the site of occurrence of the lesion and present with complex angio-architectural features, which in turn can render treatment procedures difficult. Appropriate treatment that aims to reduce the risk of intracranial bleeding and manage the patient's symptoms requires a multidisciplinary approach.

Case Presentation: The patient was a 62-year-old man who developed symptoms of progressive right-sided otalgia and tinnitus. Cross-sectional imaging revealed long-standing venous congestion with intracranial hemorrhage in the right parieto-occipital region. Moreover, cerebral angiography demonstrated multiple complex dAVFs at the right transverse sinus-sigmoid sinus (TS-SS) junction, right posterior condylar confluence (PCC), and torcula. Treatment consisted of one session of endovascular treatment, in which transarterial Onyx embolization was used to treat the dVAF at the right TS-SS junction, transvenous coil embolization for the dVAF at the right PCC, and particle embolization for both occipital arteries feeding the torcular dAVF. Postoperative improvement with favorable clinical outcomes was observed at the patient's last follow-up visit.

Conclusion: Multiple cranial dAVFs are an uncommon vascular lesion, which can present with unusual symptoms such as otalgia. Moreover, a single session of endovascular therapy can treat this lesion, ie, it can improve the patient's symptoms and provide a beneficial longterm outcome.

Keywords: dural arteriovenous fistula, condylar vein, endovascular, transvenous embolization, coils

\section{Introduction}

Cranial dural arteriovenous fistulas (dAVFs) are defined as an abnormal connection between dural feeding arteries and a dural sinus and/or leptomeningeal vein. The current hypothesis conjectures that the pathogenesis of dVAF is based on their association with venous outflow obstruction, ie, the resultant increase in venous pressure causes enlargement of the physiologic shunts between the dural arteries and sinuses that promote angioneogenesis through regional venous ischemia. They manifest with myriad signs and symptoms that differ based on their anatomical location and may be diagnosed incidentally. ${ }^{1}$ These unusual lesions are estimated to account for $15 \%$ of all intracranial vascular abnormalities. ${ }^{2}$ Cortical venous reflux, which is a sign of an aggressive lesion, increases the possibility of intracranial
Correspondence: Abdulrahman Hamad Al-Abdulwahhab

Department of Diagnostic and Interventional Radiology, King Fahd Hospital of the University, Imam

Abdulrahman Bin Faisal University,

Khobar City, Eastern Province, Saudi

Arabia

Tel +9665023337l I

Email ahAbdulwahab@iau.edu.sa
Clinical Interventions in Aging 2020:15 2313-2320

2313 
hemorrhage and is associated with a $>30 \%$ increase in the likelihood of mortality or severe disability. ${ }^{3,4}$

Borden et $\mathrm{al}^{5}$ and Cognard et $\mathrm{al}^{6}$ proposed the two most commonly used classification systems for dAVF. These systems function by stratifying dAVFs depending on the presence or absence of cortical venous reflux and venous drainage patterns. Clinically stable patients can be managed through observation with repeated enhanced cross-sectional imaging; however, prompt endovascular embolization or surgical intervention should be considered in unstable patients or those with debilitating symptoms, as successful treatment can significantly ameliorate symptoms and improve the quality of life.

We report the unique case of a patient who initially ignored right-sided otalgia and was diagnosed with multiple complex dAVFs involving the lateral sinus, torcula, and posterior condylar vein. The patient was successfully managed with a single uneventful session of endovascular embolization.

\section{Case Presentation}

A 62-year-old man without any past medical history of chronic illness, such as hypertension, diabetes mellitus, or dyslipidemia, was transferred from a primary health care clinic owing to progressive polyneuropathy, including right-sided otalgia with conductive hearing loss, dysarthria, pulsatile tinnitus, and right-sided dystonia, as noted during the clinical examination. Cross-sectional magnetic resonance imaging revealed a serpentine $\mathrm{T} 2$ signal void situated in the right parieto-occipital and anterior temporal regions (Figures 1 and 2). Susceptibility-weighted imaging revealed a multifocal blooming artifact in the right parieto-occipital area, representing intracranial bleeds. Furthermore, tortuous engorged vessels were observed in the right occipital and temporal lobes, which were related to venous congestion. Arterial spin labeling imaging demonstrated excessive blood pooling in the affected area, resembling venous congestion (Figure 2).

The diagnostic cerebral angiogram revealed a dAVF at the posterior condylar confluence (PCC), supplied by the proximal branches of the occipital artery and ascending pharyngeal artery (Figure 3). The suboccipital venous plexus and deep cervical veins provided the principal venous drainage.

Another fistula was identified in close proximity to the right transverse sinus-sigmoid sinus (TS-SS) junction, which was fed by the trans-osseous branches of the right occipital artery and petrosquamosal branch of the middle meningeal artery and drained through cortical temporal vein reflux toward the sphenopetrosal sinus and subsequently into the sylvian vein. Furthermore, another torcular dAVF was supplied by numerous fine trans-osseous branches of the distal occipital artery (left $>$ right). Moreover, filling of the posterior superior sagittal sinus or right lateral sinus was not identified on the right internal carotid angiogram (Figure 3).

The multidisciplinary treatment plan prescribed endovascular treatment using the combined transarterial and venous approach, which was performed under general anesthesia, to occlude all fistulas. The procedure was initiated by administering an intravenous bolus dose of unfractionated heparin to achieve an activated clotting time of 1.5 to 2 times the baseline value, depending on the patient's weight (as per the hospital's protocol), after positioning the guiding catheter within the right proximal external carotid artery. We decided to embolize the right TS-SS junction dAVF first. First, we passed the right petrous branch of the middle meningeal artery, followed by injection of Onyx 18 (ev3, Plymouth, MN, USA) under continuous fluoroscopic guidance, to achieve complete occlusion of the fistula. Subsequently, we used the left transfemoral venous approach to gain access to the right innominate vein and traced a prominent cervical vein to the suboccipital venous plexus. We stretched the tortuosity of the venous plexus and supported the advanced stability catheter by employing a V-18 control wire (Boston Scientific, Natick, MA, USA). The tip of the microcatheter was located within the posterior condylar sac. Complete occlusion was accomplished following the deployment of ORBIT GALAXY coils (Codman Neurovascular, Raynham, MA, USA) and HydroSoft coils (MicroVention Terumo, Tustin, CA, USA; Figure 4).

Finally, we accessed both external carotid arteries to approach the occipital artery, which contributed to the remaining torcular dAVF. A PROWLER SELECT Plus (Codman, Raynham, MA, USA) microcatheter was used to inject polyvinyl alcohol (PVA) particles of 150-250 $\mu \mathrm{m}$ (Boston Scientific, Natick, MA, USA) under continuous fluoroscopic guidance, following which complete embolization was achieved. We confirmed the presence of another shunt further along the fistula using a final control angiogram; however, we observed downstream flow in the right lateral sinus and superior sagittal sinus. 

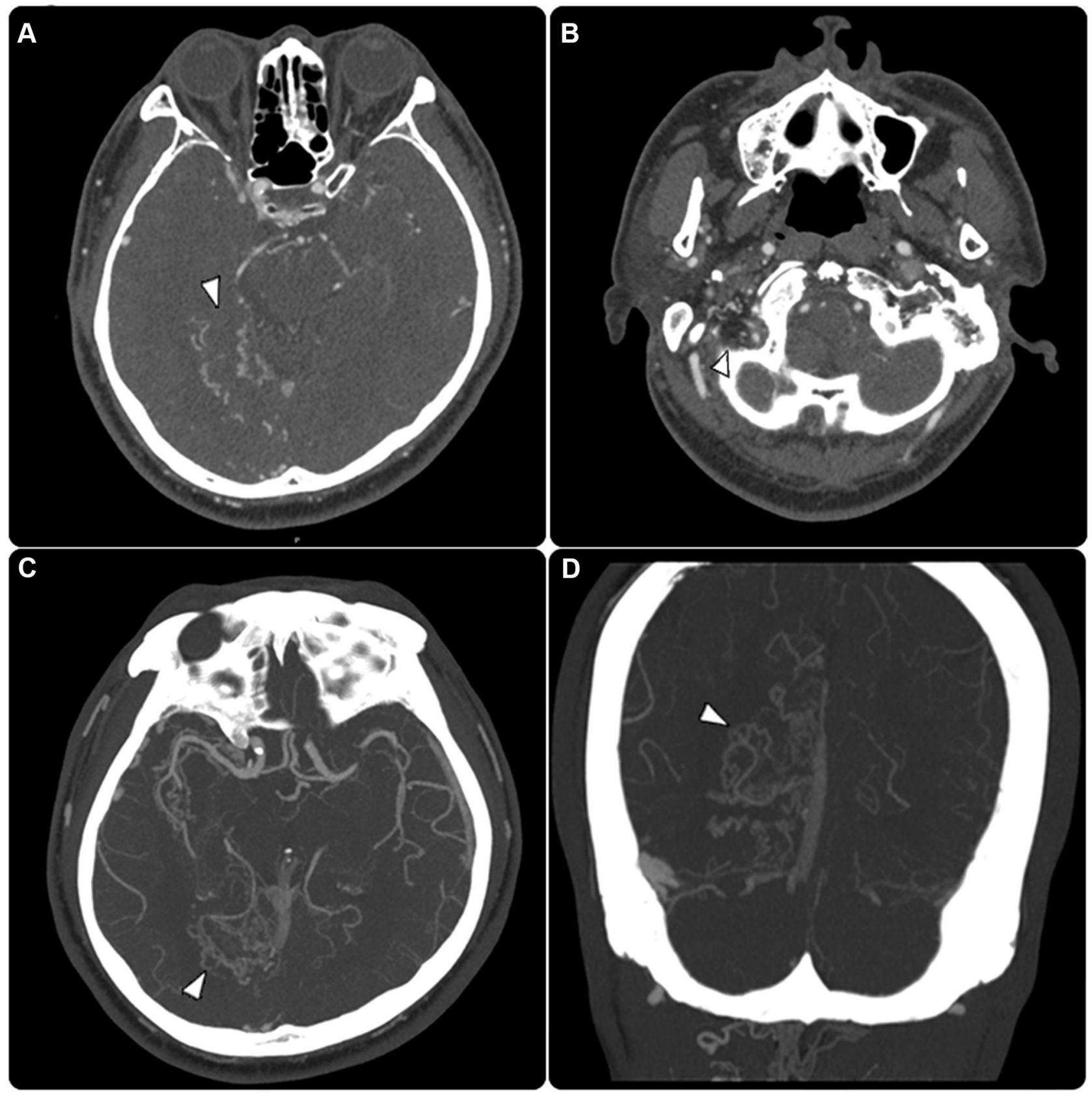

Figure I (A and B) Enhanced angiographic CT examination in and (C and D) maximum intensity projection technique showed a complex tangle of dilated and tortuous vessels of the right-sided temporoparietooccipital regions and posterior condylar area (arrowheads).

No complications were observed during or immediately after the procedure, and the patient's symptoms were resolved. The patient was followed in routine basis with otolaryngology outpatient clinic for 3 months, without any complaints. The otolaryngology team recorded their observations with an overall improvement from a clinical point of view. The patient also confirmed that the symptoms did not reappear during the last follow-up visit and that he was satisfied with the management plan.

\section{Discussion}

A dAVF is an abnormal arteriovenous communication that links arterial and venous channels within the leaflets of the dura mater. ${ }^{7}$ Although the etiology of multiple dAVFs is unknown, the occurrence of cyclical sinus thrombotic occlusion and recanalization is one of the theories postulated to explain their pathogenesis. These fistulas may emerge after angioneogenesis as micro-shunts within the dura; several risk factors are known to increase the 


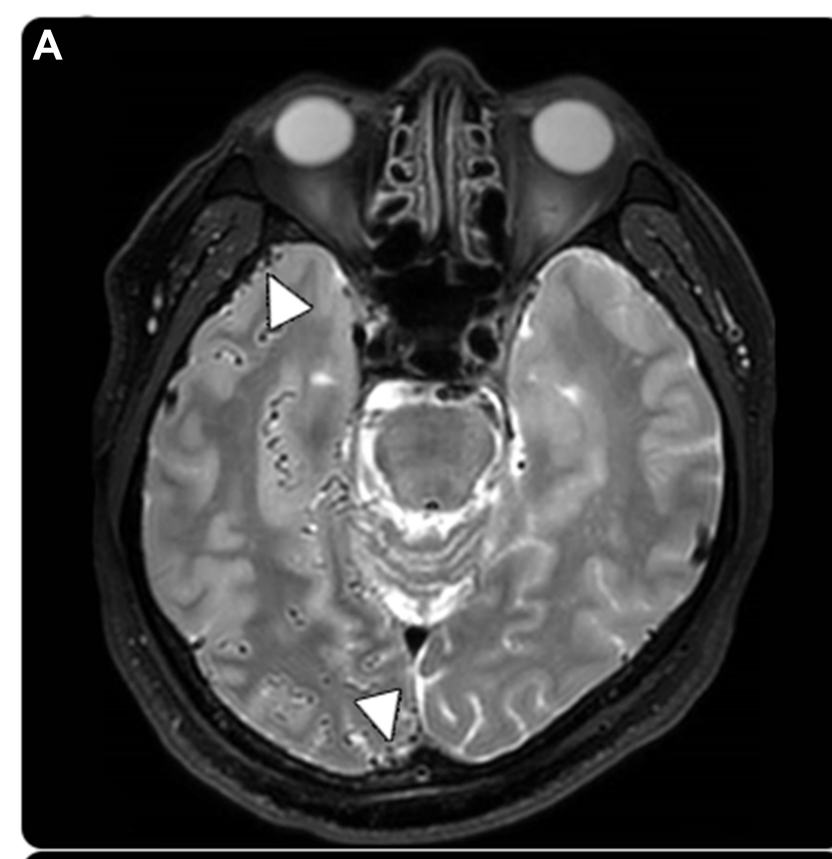

C

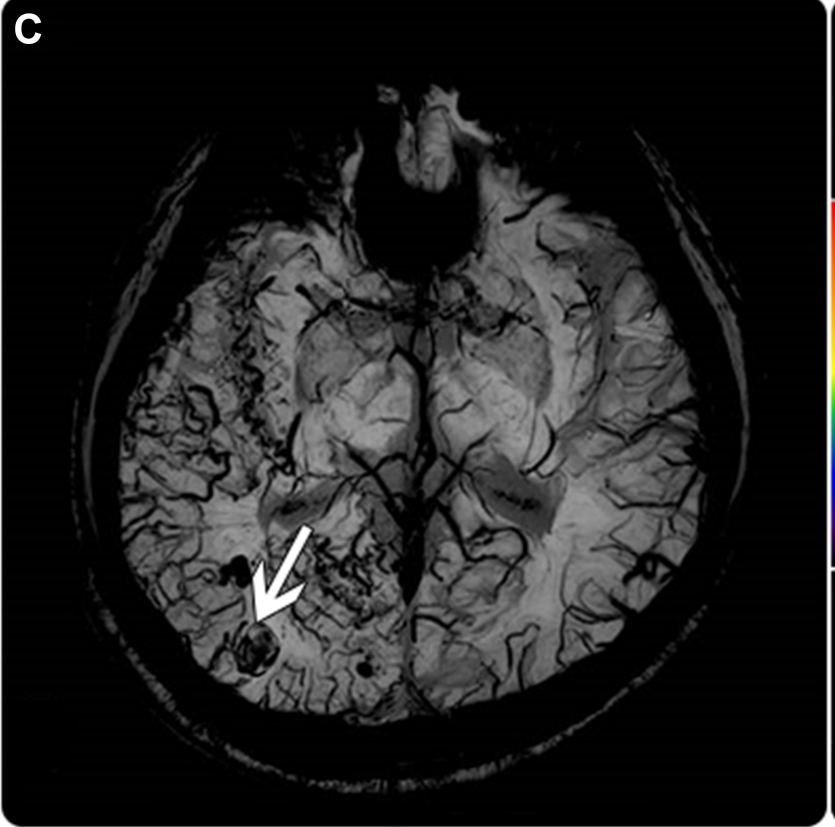

B

D

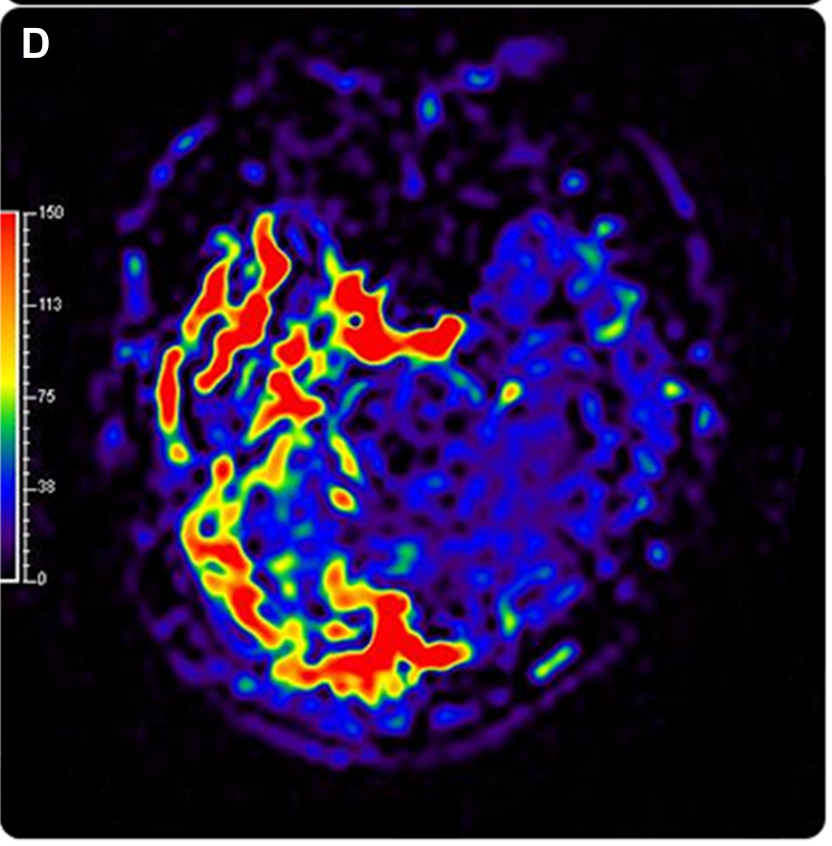

Figure 2 (A) Axial T2 weighted image demonstrates fine tortious dural vessels at the right parietooccipital and temporal region (arrowheads). (B and C) Susceptibly weighted image (SWI) showed engorged dural vessels with multifocal intraparenchymal hemorrhage in the right temporal and occipital area (arrows). (D) Arterial spin labeling (ASL) showed an increased blood pool in the right occipital and temporal region, resembling venous congestion.

incidence of such fistulas, including venous sinus thrombosis, head trauma, transcranial surgery, transsinus procedures, hyper-coagulable states, and oral contraceptive use. $^{8,9}$

The etiology of pain in dAVF is attributed to the direct communication between the dural arteries and venous sinuses or meningeal venous lacunae, with antegrade venous drainage that increases flow through the dural sinuses or venous channels; dAVFs commonly produce benign symptoms such as headaches, otalgia due to pulsatile tinnitus, and painful ophthalmoplegia due to accumulated venous drainage toward the cavernous sinus that can sometimes result in painful proptosis. ${ }^{1}$

Furthermore, multiple cranial neuropathies can occur in patients with dAVF. Vasogenic (extracellular) edema develops in the cerebral white matter in the presence of cortical venous congestion, contributing to gradual neurological impairment with epileptic seizures, Parkinsonism, 

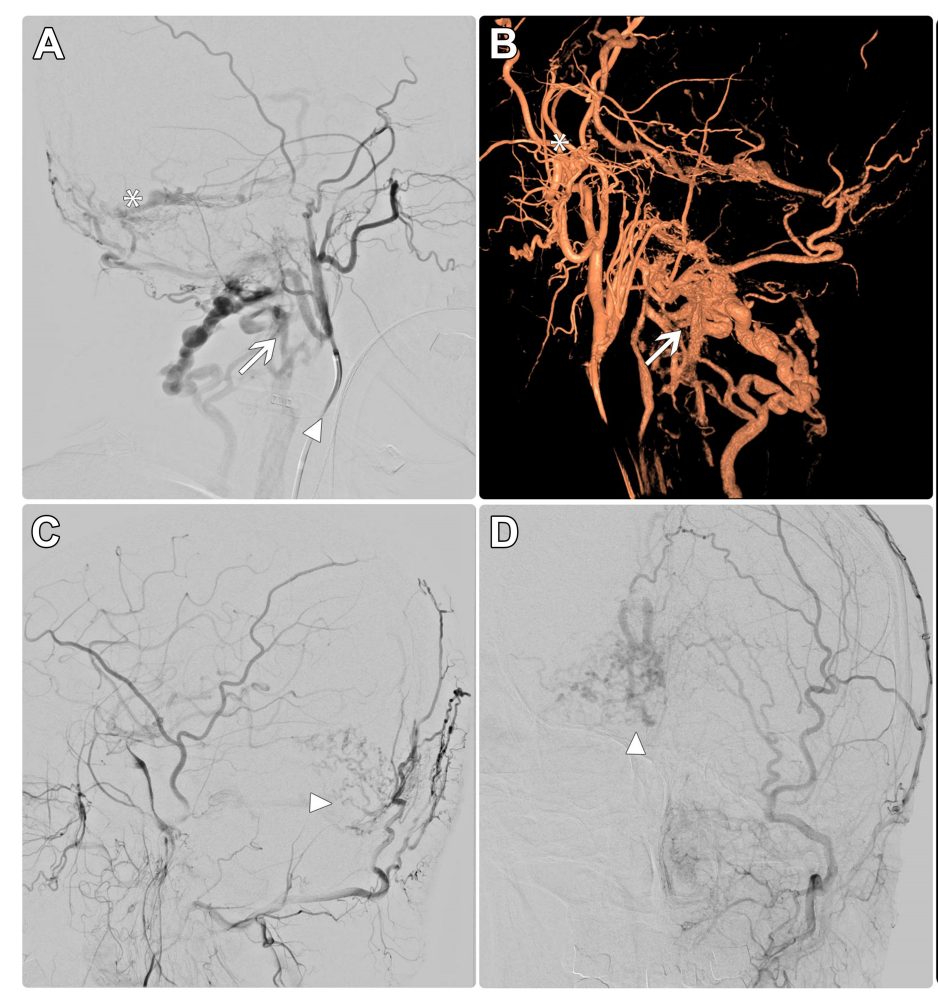

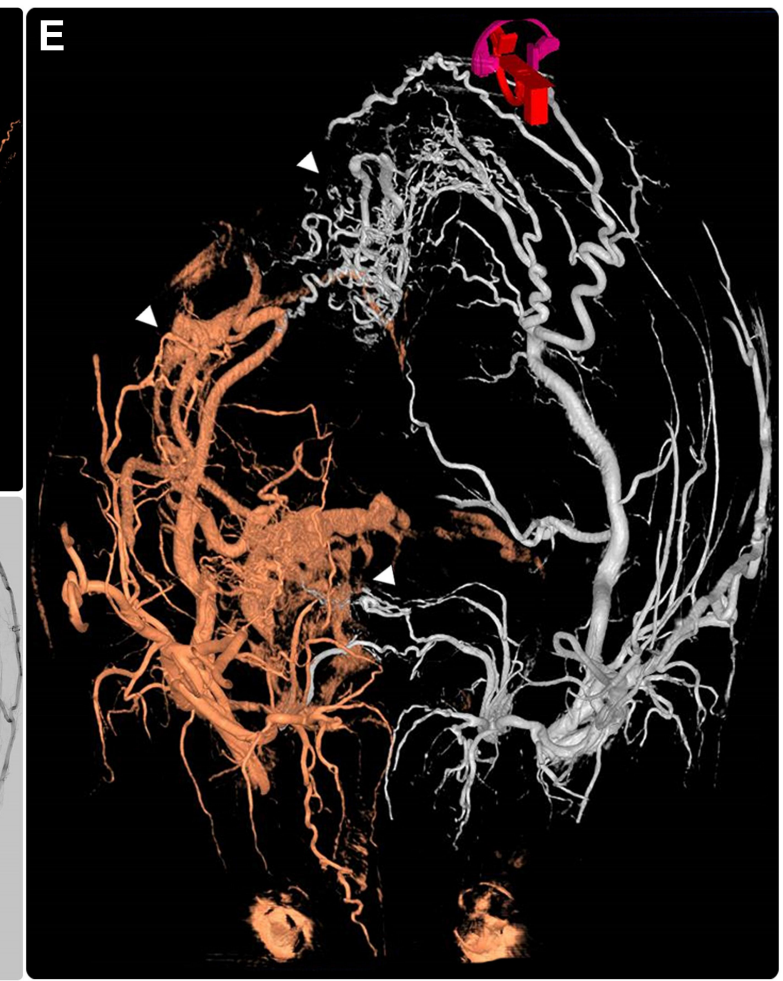

Figure 3 (A) Lateral cerebral angiogram selectively through the left external carotid artery (arrowhead) showed Torcula dAVF (asterisk) and posterior condylar vein (arrow). (B and C) Cerebral angiogram lateral view and 3D reconstruction of the right external carotid artery injection respectively showed posterior condylar vein (arrow), lateral sinus dAVF (asterisk) and the left external carotid artery (arrowhead). (D) AP view cerebral angiogram through the left external carotid artery showed Torcula dAVF (arrowhead). (E) Three dimensional both ECA angiogram (fused image) visualizes Torcula dAVF, and lateral sinus dAVF (arrowheads).

progressive cognitive impairment, cerebellar symptoms, myelopathy, and cranial nerve abnormalities. ${ }^{1}$

A multidisciplinary approach with several treatment sessions should be considered as part of the treatment plan if a case of complex cranial dAVF cannot be managed with a single session of treatment. Multiple arterial feeders, reflux into multiple cortical veins, sinus entrapment and occlusion, venous aneurysms, segmental stenosis, median or deep location, and associations with the deep venous system are specific angio-architectural considerations that can increase the complexity of the dAVF and its associated management. ${ }^{3}$

Natarajan et $\mathrm{al}^{10}$ described a treatment algorithm for complex dAVFs in which endovascular treatment was recommended as the first option. In cases of multiple dAVFs, our institution prefers the single-stage embolization approach if it is technically feasible. However, we generally recommend staged embolization if the potential risks of such an approach are too high. Moreover, we recommend treating lesions associated with cortical venous reflux or symptomatic cases first. Follow-up without urgent treatment is generally recommended in patients with small asymptomatic shunts with antegrade drainage.
Ensuring an unbiased approach for the management of these lesions and utilizing all the tools in the modern neurosurgical armamentarium, including endovascular and radiosurgical options, are essential for achieving the primary goal of interrupting the connections within the fistula. Furthermore, adequate experience and availability of the most efficient combination of methods can facilitate the application of specific approaches to assist in lowering the procedural risks.

Transarterial ONYX embolization should be the first option for dAVFs located at any site, except cavernous DAVFs. Moreover, ONYX has unique physical properties, which facilitates prolonged injections that can be better controlled, along with a more predictable penetration and higher cure rate compared to other agents. ${ }^{13,18,19}$

We used transarterial embolization using PVA particles to transiently occlude the torcular dAVF through decrease the shunt flow and thereafter temporarily resolve the patient's symptoms. Although it is not recommended to use only PVA particles, it can be used in conjunction with other procedures such as irradiation, surgery or transvenous embolization. ${ }^{14}$

Transvenous embolization (TVE) is based on thrombosis of the venous side of the fistula, which involves 

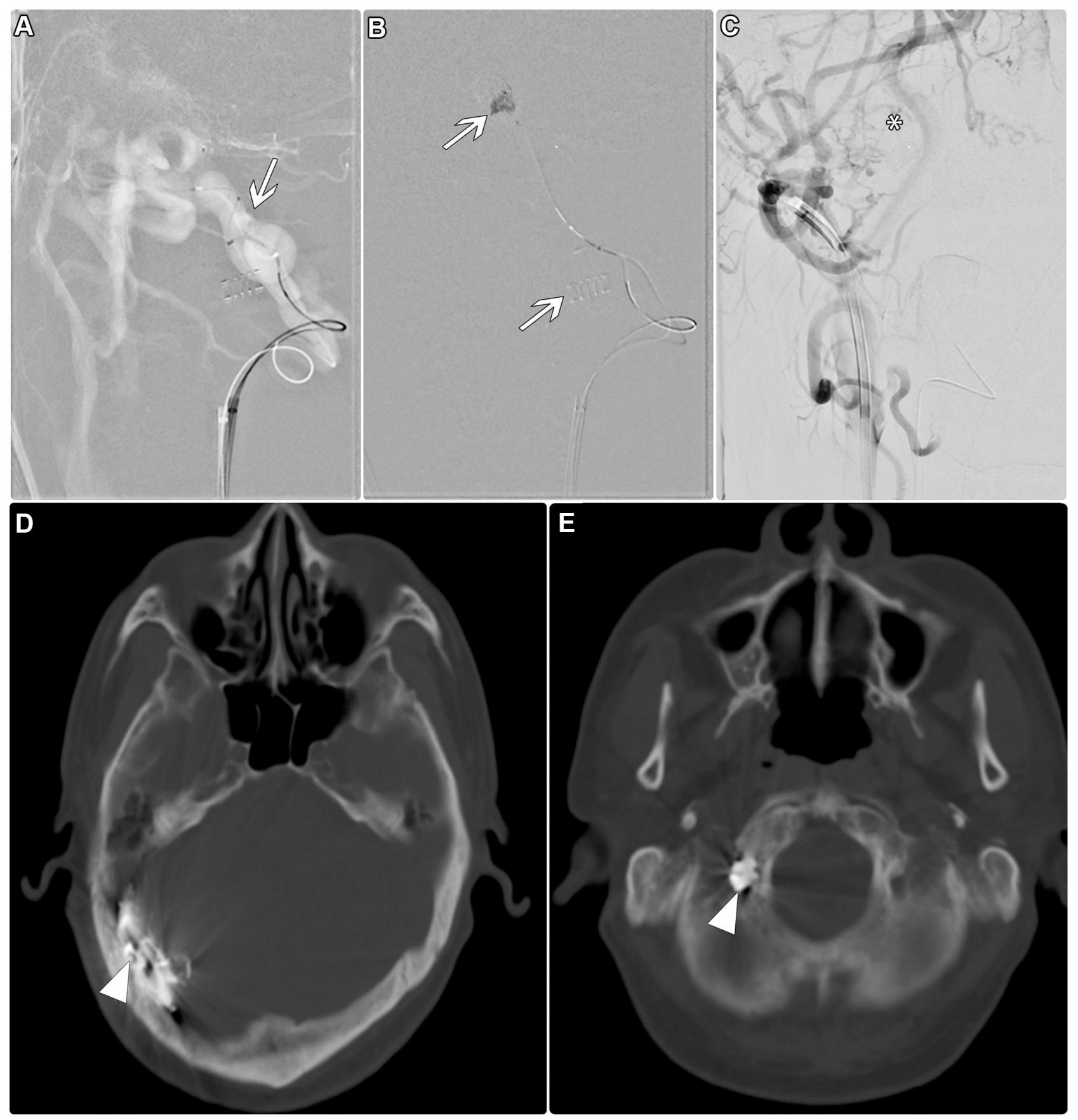

Figure 4 (A) The selective roadmap of the lower skull part shows super-selection of paravertebral venous plexus reaching to posterior condylar vein dAVF (arrow). (B) Platinum coils were deployed at the posterior condylar vein dAVF (arrows). (C) The final run shows the total obscuring of posterior condylar vein AVF (asterisk). (D and E) Post-operative computed tomography images reveal complete coil material at the location of posterior Condylar vein dAVF, with embolic material obscuring the lateral sinus Davf (arrowheads).

a part of the dural sinus. This procedure would be welltolerated if the pathological dural sinus is arterialized and does not serve as a site of drainage in normal circulation. Large venous sinuses can often be blocked without complications. It can benefit cavernous or transverse sigmoid sinus fistulas, or cranial dAVFs with multiple arterial feeders with a small or tortuous course, for which TAE would be difficult. Overall, TVE has a success rate of $71-87.5 \%{ }^{10}$

An extensive understanding of the complex vascular architecture of dAVFs is required and can facilitate the selection of the optimal treatment strategy, as performed in the posterior condylar dural fistula described in this case. Furthermore, TVE should be considered the first-line treatment approach 
Table I A Summary of Reported Cases of dAVFs Involving the Posterior Condylar Vein

\begin{tabular}{|l|l|l|l|l|l|}
\hline Case & $\begin{array}{l}\text { Age/ } \\
\text { Sex }\end{array}$ & Presentation & Feeding Arteries & Draining Vein & $\begin{array}{l}\text { Treatment/ } \\
\text { Result }\end{array}$ \\
\hline Maus V. $2016^{15}$ & $\left(^{*}, \mathrm{~F}\right)$ & Tinnitus & $\begin{array}{l}\text { Ascending pharyngeal } \\
\text { artery, Vertebral artery }\end{array}$ & $\begin{array}{l}\text { Suboccipital cavernous venous plexus, } \\
\text { Sigmoid sinus and internal jugular vein }\end{array}$ & TVE/cured \\
\hline $\begin{array}{l}\text { Kiyosue H } \\
2007^{16}\end{array}$ & $(54 y, \mathrm{M})$ & Tinnitus & $\begin{array}{l}\text { Ascending pharyngeal } \\
\text { artery, Vertebral } \\
\text { artery, Occipital artery }\end{array}$ & Sigmoid sinus, Paravertebral veins & TVE/cured \\
\hline $\begin{array}{l}\text { Mondel PK } \\
2014^{17}\end{array}$ & $(43 y$, M) & $\begin{array}{l}\text { SAH with } \\
\text { intraventricular } \\
\text { hemorrhage }\end{array}$ & $\begin{array}{l}\text { Ascending pharyngeal } \\
\text { artery, Vertebral } \\
\text { artery, bilaterally }\end{array}$ & Single medullary bridging vein \\
\hline $\begin{array}{l}\text { Shambanduram } \\
\text { SS 20I8 }\end{array}$ & $(72 y$, M) & $\begin{array}{l}\text { Severe headache, } \\
\text { vomiting and neck rigidity. } \\
\text { SAH in the left cerebello- } \\
\text { pontine angle cistern and } \\
\text { bilateral lateral ventricles. }\end{array}$ & $\begin{array}{l}\text { Posterior meningeal } \\
\text { branch of the left V3 } \\
\text { vertebral artery. }\end{array}$ & $\begin{array}{l}\text { Ipsilateral lateral medullary pontine vein } \\
\text { emptying into the anterior medullary- } \\
\text { anterior pontomesencephalic longitudinal } \\
\text { venous axis, and into the contralateral } \\
\text { superior petrosal sinus via the petrosal vein }\end{array}$ & TAE/cured \\
\hline Our case 2020 & $(67 y$, M) & $\begin{array}{l}\text { Progressive right-sided } \\
\text { tinnitus, dysarthria, and } \\
\text { slurred motion }\end{array}$ & $\begin{array}{l}\text { Proximal occipital } \\
\text { branches, Ascending } \\
\text { pharyngeal, Odontoid } \\
\text { arch distribution }\end{array}$ & $\begin{array}{l}\text { Deep cervical veins, Suboccipital venous } \\
\text { plexus }\end{array}$ & TVE/cured \\
\hline
\end{tabular}

Note: *Not mentioned.

Abbreviations: M, male; F, female; y, year-old; SAH, subarachnoid hemorrhage; TVE, transvenous embolization; TAE, transarterial embolization.

for condylar dAVFs, because it is safe and effective. ${ }^{12}$ Catheterization of the cervical venous plexus is classified as a difficult procedure, owing to the tortuous venous route.

We think this case is significantly unique because of the atypical symptoms observed at first presentation, before the appearance of venous congestion and intracranial hemorrhage. Few similar cases have been reported in the literature. ${ }^{20}$ We also found a rare dural fistula in the posterior condylar vein, which was treated successfully using transvenous coil embolization (Table 1).

The Onyx embolic material is recommended for TAE of dAVFs because it is superior to glue or coils, with respect to safety and facilitates a high rate of complete obliteration. Moreover, it is not associated with neurological morbidity or mortality. ${ }^{13}$

\section{Conclusion}

The diagnosis and treatment of multiple cranial dAVFs remain challenging, despite the rapid advancements in surgical technology and techniques. A multidisciplinary strategy should be implemented, after a thorough clinical evaluation, aided by innovative pre- and intra-operative imaging techniques. This will increase the amenability of endovascular management for treating these lesions and allow clinicians and patients to weigh treatment risks against the expected clinical course. In our case, a single endovascular treatment session accomplished favorable long-term outcomes for multiple complex dAVFs.

\section{Abbreviations}

dAVF, dural arteriovenous fistula; PCC, posterior condylar confluence; TAE, transarterial embolization; TS-SS, transverse sinus-sigmoid sinus; TVE, transvenous embolization.

\section{Data Sharing Statement}

Not applicable. This is a case review of publicly available information.

\section{Ethics Approval and Informed Consent}

As per the institutional review board, case reports do not require ethical approval, provided no patient identifiers appear in the report. A written informed consent has been provided by the patient to have the case details and any accompanying images published.

\section{Consent for Publication}

Consent for publication of the manuscript and the related patient information has been obtained. 


\section{Funding}

This study did not receive any specific grant from funding agencies in the public, commercial, or not-for-profit sectors.

\section{Disclosure}

The authors declare that they have no conflict of interest.

\section{References}

1. Signorelli F, Gory B, Maduri R, et al. Intracranial dural arteriovenous fistulas: a review of current management based on emerging knowledge. J Neurosurg Sci. 2015;61(2):193-206. doi:10.23736/ s0390-5616.16.03168-4

2. Ha SY, Kwon YS, Kim BM, Kim DI, Kim DJ. Clinical and angiographic characteristics of multiple dural arteriovenous shunts. AJNR Am J Neuroradiol. 2012;33(9):1691-1695. doi:10.3174/ajnr.a3054

3. Priola SM, Ku JC, Pasarikovski CR, Yang VX, da Costa L. Angioarchitecture of complex cranial dural arteriovenous fistulas: a single centre retrospective review of treatment modalities and outcomes. $J$ Clin Neurosci. 2020;76:87-99. doi:10.1016/j.jocn.2020.04.037

4. Lasjaunias P, Chiu M, Ter Brugge K, Tolia A, Hurth M, Bernstein M. Neurological manifestations of intracranial dural arteriovenous malformations. $J$ Neurosurg. 1986;64(5):724-730. doi:10.3171/ jns.1986.64.5.0724

5. Borden JA, Wu JK, Shucart WA. A proposed classification for spinal and cranial dural arteriovenous fistulous malformations and implications for treatment. $J$ Neurosurg. 1995;82(2):166-179. doi:10.3171/ jns.1995.82.2.0166

6. Cognard C, Gobin YP, Pierot L, et al. Cerebral dural arteriovenous fistulas: clinical and angiographic correlation with a revised classification of venous drainage. Radiology. 1995;194(3):671-680. doi:10.1148/radiology.194.3.7862961

7. Shownkeen H, Yoo K, Leonetti J, Origitano TC. Endovascular treatment of transverse-sigmoid sinus dural arteriovenous malformations presenting as pulsatile tinnitus. Skull Base. 2001;11(01):013-24. doi:10.1055/s-2001-12782

8. Kiyosue H, Tanoue S, Okahara M, Yamashita M, Nagatomi H, Mori H. Recurrence of dural arteriovenous fistula in another location after selective transvenous coil embolization: report of two cases. AJNR Am J Neuroradiol. 2002;23:689-692.

9. Mendonca N, Santos G, Duro D, Machado E, Goulao A, Santana I. Multiple dural arteriovenous fistulas presenting as rapidly progressive dementia. Neurologist. 2012;18(3):130-132. doi:10.1097/nrl.0b013e318251e695
10. Natarajan SK, Ghodke B, Kim LJ, Hallam DK, Britz GW, Sekhar LN. Multimodality treatment of intracranial dural arteriovenous fistulas in the Onyx era: a single center experience. World neurosurgery. 2010;73(4):365-79. doi:10.1016/j.wneu.2010.01.009

11. Hu YC, Newman CB, Dashti SR, Albuquerque FC, McDougall CG. Cranial dural arteriovenous fistula: transarterial onyx embolization experience and technical nuances. J Neurointerv Surg. 2011;3 (1):5-13. doi:10.1136/jnis.2010.003707

12. Hellstern V, Aguilar-Pérez M, Schob S, et al. Endovascular treatment of dural arteriovenous fistulas of the anterior or posterior condylar vein. Clin Neuroradiol. 2019;29(2):341-349. doi:10.1007/s00062018-0669-1

13. Maus V, Söderman M, Rodesch G, Kabbasch C, Mpotsaris A. Endovascular treatment of posterior condylar canal dural arteriovenous fistula. BMJ Case Rep. 2016;2016:bcr2016012384. doi:10.1136/ bcr-2016-012384

14. Kiyosue H, Okahara M, Sagara Y, et al. Dural arteriovenous fistula involving the posterior condylar canal. AJNR Am J Neuroradiol. 2007;28(8):1599-1601. doi:10.3174/ajnr.a0606

15. Maus V, Söderman M, Rodesch G, Kabbasch C, Mpotsaris A. Endovascular treatment of posterior condylar canal dural arteriovenous fistula. Case Reports. 2016;2016:bcr2016012384. doi:10.1136/ bcr-2016-012384

16. Kiyosue H, Okahara M, Sagara Y, Tanoue S, Ueda S, Mimata C, Mori H. Dural arteriovenous fistula involving the posterior condylar canal. American journal of neuroradiology. 2007 Sep 1;28(8):1599-601. doi:10.3174/ajnr.a0606

17. Mondel PK, Saraf R, Limaye US. Acute subarachnoid hemorrhage in posterior condylar canal dural arteriovenous fistula: imaging features with endovascular management. Case Reports. 2014 Jul 2;2014: bcr2014011273. doi: $10.1136 /$ bcr-2014-011273

18. Shambanduram SS, Devarajan Sebastian LJ, Jain N, Garg A, Gaikwad SB. Management of a rare case of posterior condylar canal dural arteriovenous fistula presenting with subarachnoid haemorrhage: A case report and review of literature. Interventional Neuroradiology. 2018;24(2):206-9. doi:10.1177/1591019917743703

19. Baharvahdat H, Ooi YC, Kim WJ, Mowla A, Coon AL, Colby GP. Updates in the management of cranial dural arteriovenous fistula. Stroke Vasc Neurol. 2020;5(1):50-58. doi:10.1136/svn-2019-000269

20. Ahmed W, Connor S, Obholzer R, Pai I. A dural arteriovenous fistula associated with an encephalocele presenting as otitis media with effusion. J Laryngol Otol. 2018;1-4. doi:10.1017/S00222151180 01822
Clinical Interventions in Aging

\section{Publish your work in this journal}

Clinical Interventions in Aging is an international, peer-reviewed journal focusing on evidence-based reports on the value or lack thereof of treatments intended to prevent or delay the onset of maladaptive correlates of aging in human beings. This journal is indexed on PubMed Central, MedLine, CAS, Scopus and the Elsevier
Bibliographic databases. The manuscript management system is completely online and includes a very quick and fair peer-review system, which is all easy to use. Visit http://www.dovepress.com/ testimonials.php to read real quotes from published authors. 